\title{
Thermographic Analysis of Stress Distribution in Welded Joints
}

\author{
T. Piršić ${ }^{1}$, L. Krstulović - Opara ${ }^{2}$, Ž. Domazet ${ }^{3}$ \\ 1,2,3 Faculty of Electrical Engineering, Mechanical Engineering and Naval Architecture \\ University of Split, Croatia
}

\begin{abstract}
The fatigue life prediction of welded joints based on S-N curves in conjunction with nominal stresses generally is not reliable. Stress distribution in welded area affected by geometrical inhomogeneity, irregular welded surface and weld toe radius is quite complex, so the local (structural) stress concept is accepted in recent papers. The aim of this paper is to determine the stress distribution in plate type aluminum welded joints, to analyze the reliability of TSA (Thermal Stress Analysis) in this kind of investigations, and to obtain numerical values for stress concentration factors for practical use. Stress distribution in aluminum butt and fillet welded joints is determined by using the three different methods: strain gauges measurement, thermal stress analysis and FEM. Obtained results show good agreement - the TSA mutually confirmed the FEM model and stresses measured by strain gauges. According to obtained results, it may be stated that TSA, as a relatively new measurement technique may in the future become a standard tool for the experimental investigation of stress concentration and fatigue in welded joints that can help to develop more accurate numerical tools for fatigue life prediction.
\end{abstract}

\section{Introduction}

Over the past 20 years extensive testing and analysis of the fatigue of welded aluminum alloys have been undertaken, resulting with the various recommendations for fatigue design and fatigue life prediction of welded joints. Three main methods for design and remaining-life assessments of aluminum alloy welded structures are proposed in standards and literature:

- S-N curves for specific welded joints based on nominal stresses. The most common approach is to use $\mathrm{S}-\mathrm{N}$ curves obtained from fatigue tests on specimens containing the weld detail of interest. The design curve is usually statistical lower bound to experimental data, typically mean - 2 standard deviations of $\log$ N. Since the S-N curves refer to particular weld details, there is no need to quantify the local stress concentration effect of the weld detail.

- S-N curves for welds based on hot spot stresses. The structural hot spot stress is the linear or quadratic extrapolation of strains measured at two or three points in front of the weld toe. In the recommendations of the International Institute of Welding (IIW) [1], distances of the reference points from the weld toe of $0.4 \mathrm{t}$ and $1.0 \mathrm{t}$ or $0.4 \mathrm{t}, 0.9 \mathrm{t}$ and $1.4 \mathrm{t}$ are recommended, where $\mathrm{t}$ is the plate thickness. Quadratic extrapolation over reference points at distances from the weld toe $(4,8$, and $12 \mathrm{~mm}$ ) is recommended. 
- linear elastic fracture mechanics (LEFM) where fatigue crack growth data are used to calculate stress intensity factor and remaining fatigue life of component that contains the crack. The rate of fatigue crack growth under cyclic loading is expressed by the range of stress intensity factor $(\Delta K)$ through the Paris-Erdogan power law. The fatigue crack propagation life can be calculated by integrating Paris-Erdogan equation between the initial crack length $a_{\text {i }}$ and the final crack length at failure $a_{\text {f. }}$ The failure criteria is chosen when the effective range of stress-intensity factor has exceeded the fracture toughness of the material or the depth of the semi-elliptical surface crack in the through-thickness direction reaches a half of the plate thickness.

Development of thermal cameras based on the focal point array sensors, enabled a fast acquisition of thermal phenomena in material, reaching the acquisition frequencies up to $360 \mathrm{~Hz}$. As compression/expansion of material causes heat increase/decrease, this phenomena described by Lord Kelvin in 1850 is used in interpreting the thermal flashes of cyclic loaded body at the quasi-adiabatic state (reached at approx $10 \mathrm{~Hz}$ ), as stresses. Similar to strain gauges, the stresses at the surface are acquired, but for the case of TSA showing the full field stress distribution on the object surface. Whit this method stress concentration can be evaluated, critical zones can be detected, and crack growth can be monitored. There are other approaches in life time prediction based on the thermal changes appearing together with plastic yielding and failure of specimen. In [2 - 3] is even whole $\mathrm{S}-\mathrm{N}$ diagram constructed from only one specimen using a quite simple Risitano method. The advantages and drawbacks of these methods are widely discussed in literature pointing out that major problem is stress concentration due to irregular surface of weld toe. Besides widely accepted methods of stress concentration determination (FEM and strain gauge measurement) TSA, as a relatively new, fast and accurate method can be used. Reliability, advantages and drawbacks of this method in a case of welded joints are analyzed in further text.

\section{Experimental procedure}
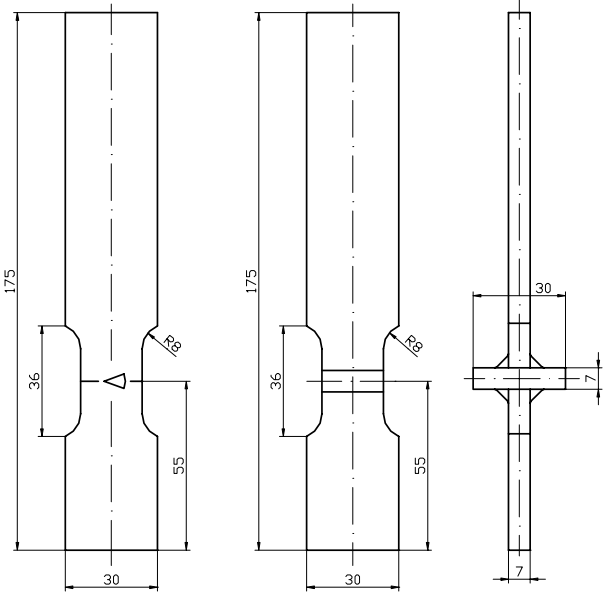

Fig. 1. Dimensions and shape of specimens
Two kinds of plate specimens are used: specimens with butt weld, and specimens with fillet weld (double - sided transverse attachment joint), Figure 1, 2. Material of the specimens is $\mathrm{AlMg} 4.5 \mathrm{Mn}$ (ASTM 5083) aluminum alloy, with yield strength $\mathrm{R}_{\mathrm{e}}=217 \mathrm{MPa}$, ultimate strength $\mathrm{R}_{\mathrm{m}}=318 \mathrm{MPa}$ and modulus of elasticity $\mathrm{E}=72000 \mathrm{MPa}$. Usual MIG welding process with AlMg5 aluminum alloy as filler material is used. Specimens are subjected to axial constant amplitude loading at various stress levels (stress ratio $\mathrm{R}=\sigma_{\min } / \sigma_{\max }=0$ ) up to yield strength. Two strain gauges (type HBM 1.5/120 LY13), Figure 2, are attached at appropriate distance from weld toe [1] to determine the hot spot stress. Hot spot stresses are calculated by extrapolating the values of two measured stresses at the distance of $t / 2$ and $3 t / 2$ from weld toe (where $t$ is plate thickness), [4]. The surfaces of the specimens were painted in black (in order to get a greater thermal emisivity), and thermographic images were acquired every $25 \mathrm{~s}$ by means of a medium wave infrared camera with cooled focal point array, FLIR SC5000. Linear elastic FEM 3D model, Figure 3, consists of 1347 tetrahedrons, with mesh refinement in welded area. By it's nature, FEM model is simplified - different mechanical properties of parent metal, heath affected zone and melted metal, axial and angular misalignment and tensile residual stresses were not taken into account. 

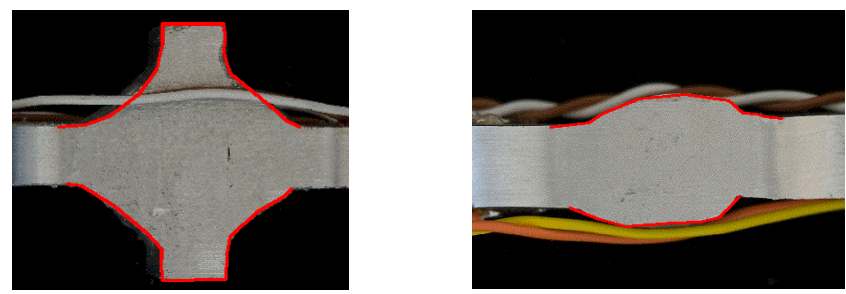

Fig. 2. Approximation of weld surface by NURBS

The irregular shape of weld surface and weld toe radius are determined by macro photography and approximated by NURBS (Non Uniform Rational Besier's curves), Figure 2, 3. Measured notch radius at weld toe is approximately $1 \mathrm{~mm}$, what is in accordance with recommendations $[1,4]$.

Tests were performed using an Instron $50 \mathrm{kN}$ servo-hydraulic load machine at frequency $\mathrm{f}=10 \mathrm{~Hz}$. Stresses were measured by strain gauges and determined by TSA simultaneously at each load level.
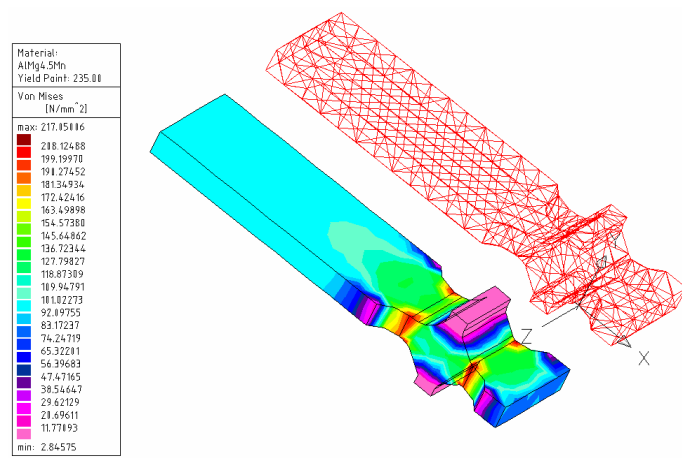

Fig. 3. FEM model of fillet welded joint

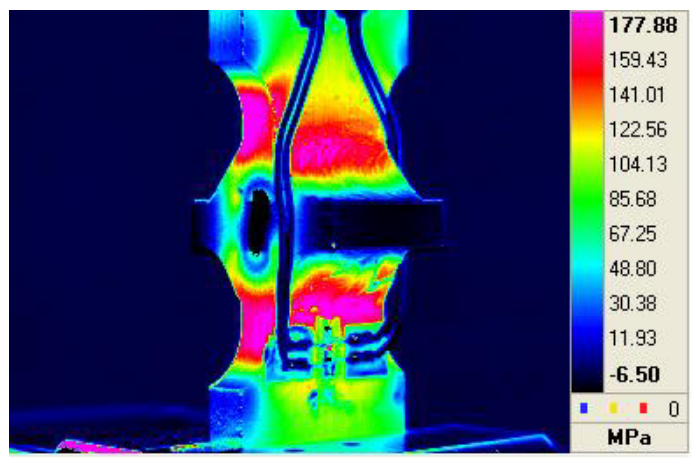

Fig. 4. Example of TSA

It should be noted that strain gauge, due to generated heat, disables the TSA measurement in the area directly under the gauge. In order to compare the results, stresses at the border of strain gauge and base material are taken into account.

\section{Comparison of obtained results}

Energy dissipation, due to the elastic stresses in the structure, can be detected with an infrared thermal imaging camera. The TSA presented here is based on the FLIR SC5000 infrared (IR) camera, Lockin [6], and the Altair-Li software [7]. The Lockin is a hardware component that links thermal image with the load source signal, what together with the software enables better filtering and evaluation of stress distribution images. Due to the basic principles of the TSA, the obtained image represents first invariant of stresses on the body surface.

Results of strain gauge measurement, FEA calculations and TSA are presented in Table 1. and Figure 5 (for fillet welded joints) and in Table 2. and Figure 6 for but welded joints. 
Table 1. Comparison of measured and calculated stresses - fillet welded joint

\begin{tabular}{|c|c|c|c|c|c|c|}
\hline $\begin{array}{c}\text { Load } \\
(\mathrm{kN})\end{array}$ & $\begin{array}{c}\text { Nominal } \\
\text { stress }(\mathrm{MPa})\end{array}$ & $\begin{array}{c}\text { TSA } \\
(\mathrm{MPa})\end{array}$ & $\begin{array}{c}\text { Gauge 1 } \\
(\mathrm{MPa})\end{array}$ & $\begin{array}{c}\text { Gauge 2 } \\
(\mathrm{MPa})\end{array}$ & $\begin{array}{c}\text { Hot spot } \\
(\mathrm{MPa})\end{array}$ & $\begin{array}{c}\text { FEM } \\
(\mathrm{MPa})\end{array}$ \\
\hline 8 & 57 & 70 & 63 & 55 & 67 & 72 \\
\hline 10 & 71 & 78 & 78 & 68 & 83 & 80 \\
\hline 12 & 86 & 102 & 94 & 81 & 100 & 104 \\
\hline 14 & 100 & 109 & 109 & 95 & 116 & 113 \\
\hline 16 & 114 & 126 & 124 & 108 & 132 & 130 \\
\hline 18 & 128 & 141 & 140 & 122 & 149 & 144 \\
\hline 20 & 143 & 168 & 153 & 132 & 163 & 172 \\
\hline
\end{tabular}

Table 2. Comparison of measured and calculated stresses - butt welded joint

\begin{tabular}{|c|c|c|c|c|c|c|}
\hline $\begin{array}{c}\text { Load } \\
(\mathrm{kN})\end{array}$ & $\begin{array}{c}\text { Nominal } \\
\text { stress (MPa) }\end{array}$ & $\begin{array}{c}\text { TSA } \\
(\mathrm{MPa})\end{array}$ & $\begin{array}{c}\text { Gauge 1 } \\
(\mathrm{MPa})\end{array}$ & $\begin{array}{c}\text { Gauge 2 } \\
(\mathrm{MPa})\end{array}$ & $\begin{array}{c}\text { Hot spot } \\
(\mathrm{MPa})\end{array}$ & $\begin{array}{c}\text { FEM } \\
(\mathrm{MPa})\end{array}$ \\
\hline 8 & 45 & 48 & 47 & 41 & 50 & 49 \\
\hline 10 & 57 & 58 & 58 & 50 & 62 & 60 \\
\hline 12 & 68 & 68 & 69 & 60 & 73 & 72 \\
\hline 14 & 80 & 83 & 81 & 70 & 86 & 85 \\
\hline 16 & 91 & 98 & 92 & 80 & 98 & 102 \\
\hline 18 & 102 & 109 & 104 & 90 & 111 & 115 \\
\hline 20 & 114 & 120 & 115 & 100 & 122 & 124 \\
\hline
\end{tabular}

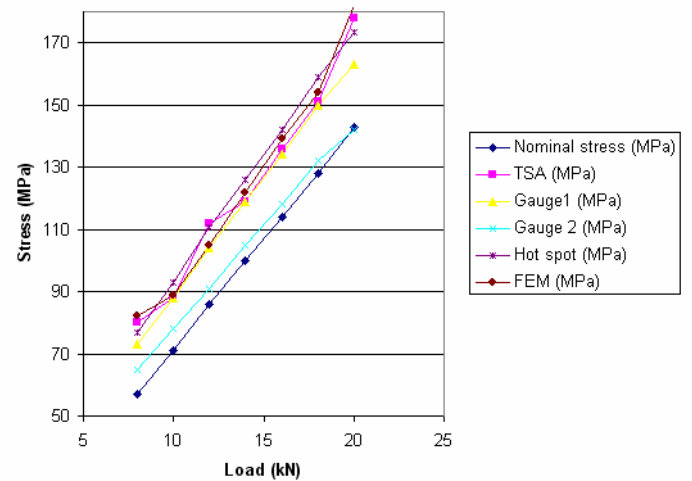

Fig. 5. Comparison of results for fillet welded joints

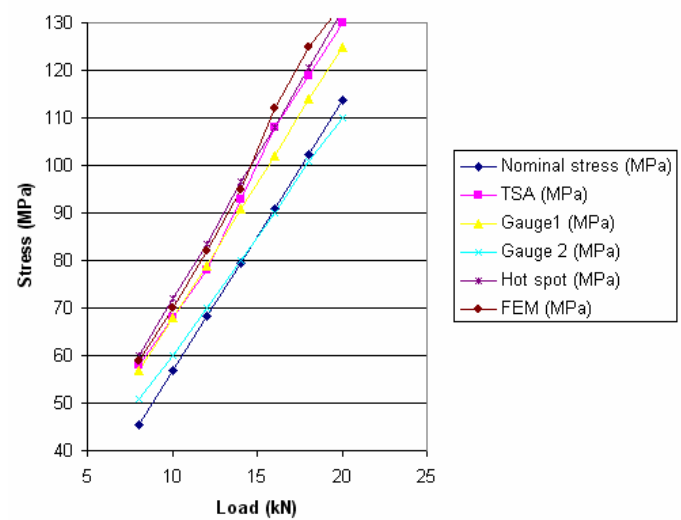

Fig. 6. Comparison of results for butt welded joints

Linearity of measured and calculated data on different stress levels is obvious and expected due to linear dependence of stress and strain beyond the yield strength. Calculated elastic stress concentration factors $\mathrm{K}_{\mathrm{t}}$ in the vicinity of the of weld toe based on different methods are in good agreement. For fillet welded joints: $\mathrm{K}_{\mathrm{t}}=1,26$ (based on FEA), $\mathrm{K}_{\mathrm{t}}=1,27$ (based on Hot spot stress) and $\mathrm{K}_{\mathrm{t}}=1,25$ (based on TSA). For butt welded joints: $\mathrm{K}_{\mathrm{t}}=1,26$ (based on FEA), $\mathrm{K}_{\mathrm{t}}=1,22$ (based on Hot spot stress and $\mathrm{K}_{\mathrm{t}}=1,18$ (based on TSA).

Another advantage of TSA and Altair-Li software is possibility of accurate determination of stress profile along the desired axes (or plane), Figure 6 and 7. That can be useful not only for stress field analysis, but also for determination of construction weak points, optimization, predictions and monitoring. 

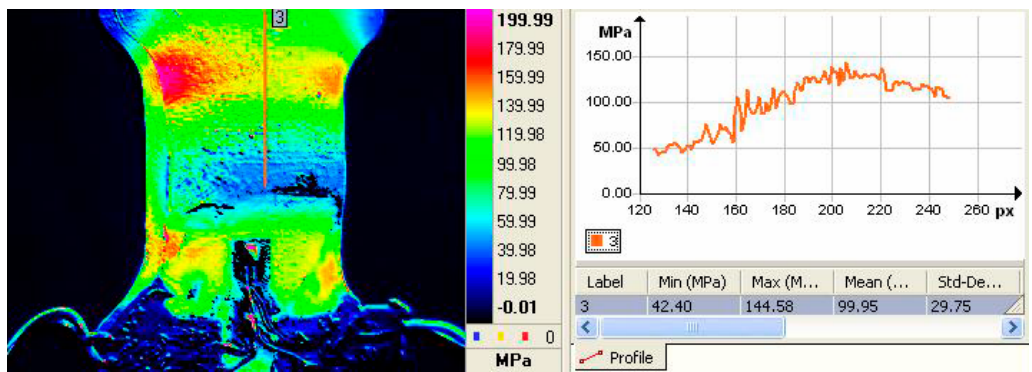

Fig. 6. Stress profile along the axis of symmetry for the butt welded joint

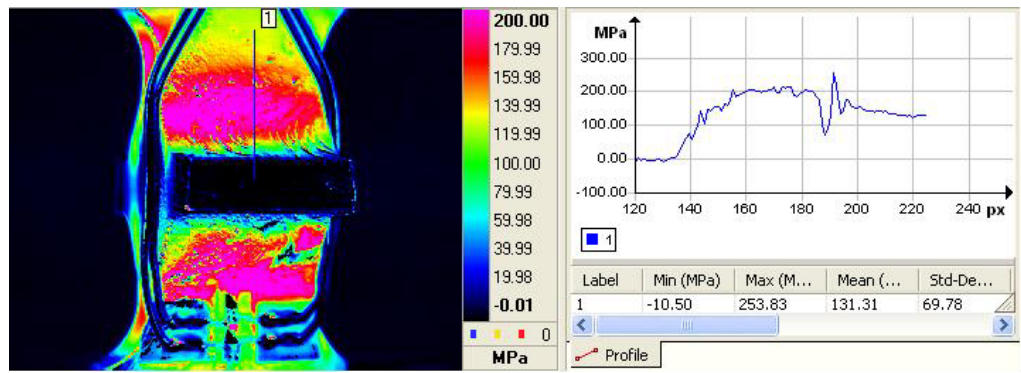

Fig. 7. Stress profile along the axis of symmetry for the fillet welded joint

It should be noted that stress field distribution is very sensitive to the geometrical characteristics of the welded joint (i.e., weld toe radius, flank angle and weld size), what is visible at the TSA images (Fig 4). The weld reinforcement shape depends on the welding parameters, the operating conditions and the skill of the welder. The weld reinforcement shape (particularly the weld toe radius) varies from joint to joint even in well-controlled manufacturing operations. Therefore, presented results can not be generalized - they are validated for AlMg4.5Mn aluminum alloy welded by usual MIG process - further investigations are necessary for different materials and for various welding processes.

\section{Conclusion}

The presented non-destructive method enables obtaining information about the stress concentration and corresponding critical zones in the weld geometry. Obtained results show good agreement, with the trend of slightly lower stresses measured by strain gauges. That was expected, due to fact that in the areas of high stress gradient strain gauges can not measure maximum (or peak) stress - measured stress is average value of stress field under the stress gauge surface.

The TSA mutually confirmed the FEM model and stresses measured by strain gauges, proving that the numerical FEM model as a reliable tool in modeling the stress distribution in plate type welded joints.

The estimation of stress field and fatigue life prediction of welded joints are complex tasks due to interactions of irregular shape of welded surface, welding residual stresses, misalignments and distortions of welded parts, and different mechanical properties of parent metal, melted metal and material in heath affected zone. The TSA, as a full field method, helps to make a numerical analysis faster and predictable, without need for extensive iterative investigations, what reduces both time and costs, provides good basis for a wide range of investigations and eliminates or reduces the need of expensive destructive tests. 
The development of infrared technologies, with cameras based on the Focal Point Array (FPA) sensors, enabled acquisition at higher frequencies. The infrared equipment and corresponding software represent a reliable and accurate method to determine the stress distribution of cyclically loaded structures. The stress concentration zones, as the main source of fatigue failure, are clearly visible and distinguishable enabling the more accurate life time prediction.

\section{Acknowledgments}

The support from the Croatian Ministry of Science, Education and Sports project "Fatigue strength of constructions and materials" is gratefully acknowledged.

\section{References}

1. A. Hobbacher, editor, Recommendations for fatigue design of welded joints and components. IIW Doc XIII-2151r1-07/XV-1254r1-07. Int. Inst. of Welding (2007)

2. G. La Rosa, A. Risitano, Thermographic methodology for rapid determination of the fatigue limit of materials and mechanical components, International Journal of Fatigue, 22, 65-73, (2000)

3. G. Fargione, A. Geraci, G. La Rosa, A. Risitano, Rapid determination of the fatigue curve by the thermographic method, International Journal of Fatigue, 24, 11-19, (2002)

4. D. Radaj, C. M. Sonsino, W. Fricke, Recent developments in local concepts of fatigue assessment of welded joints, Int. J. of Fatigue 31 (2009) 2-11

5. C. Morgenstern, C. M. Sonsino, A. Hobbacher, F. Sorbo, Fatigue design of aluminium welded joints by local stress concept with the fictitious notch radius of $r_{f}=1 \mathrm{~mm}$, Int. J. of Fatigue (2006) 28:881-90

6. L. M. Haldorsen, Thermoelastic stress analysis system developed for industrial applications, Ph.D. Thesis, University of Aalborg, Institute of mechanical engineering, (1998).

7. Altair-Li - FLIR.

http://www.flir.com/uploadedFiles/Thermography/MMC/Brochures/1558641/15 58641 EN.pdf 